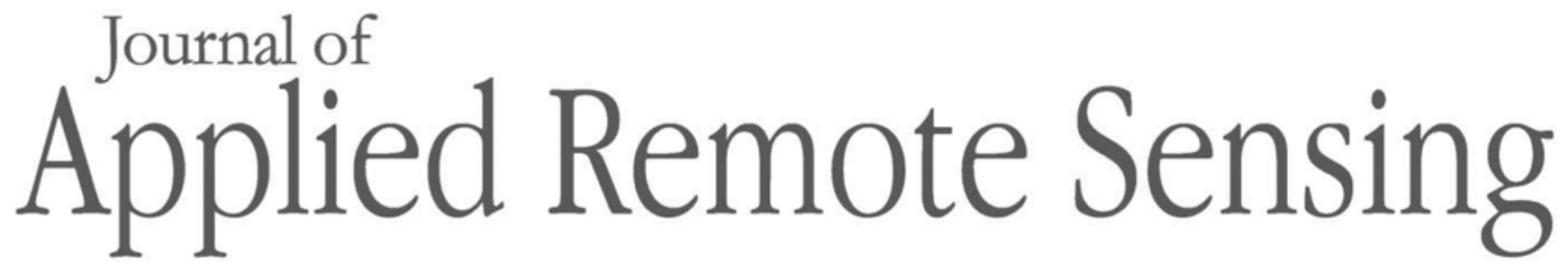

RemoteSensing.SPIEDigitalLibrary.org

\title{
Underwater optical detection after passage of tropical storm
}

\author{
Peter C. Chu \\ Chenwu Fan
}

QD Peter C. Chu, Chenwu Fan, "Underwater optical detection after passage of tropical storm," J. Appl. Remote Sens. 13(4), 047502 (2019), doi: 10.1117/1.JRS.13.047502. 


\title{
Underwater optical detection after passage of tropical storm
}

\author{
Peter C. Chu* and Chenwu Fan \\ Naval Postgraduate School, Naval Ocean Analysis and Prediction Laboratory, \\ Department of Oceanography, Monterey, California, United States
}

\begin{abstract}
Optical detection systems have the potential to get around some limitations of acoustic detection systems, especially with increased fleet and port security in noisy littoral waters. Identification of environmental effects especially tropical storms on underwater optical detection is a key to the success. A typhoon-influenced area is chosen in the western North Pacific Ocean with high ocean transparency and low seasonal optical variability. Underwater inherent optical properties (IOPs) such as the beam attenuation coefficient for $470 \mathrm{~nm}$ light are measured in the selected region from the U.S. Naval Oceanographic Office sea gliders deployed after super typhoon Guchol's (June 7 to 20, 2012) passage from June 25 to 30, 2012, and with no typhoon activity from January 9 to February 28, 2014. The observed two sets (with and without typhoon) of IOPs are taken as the input into the Navy's electro-optical detection simulator. The simulation shows low detection after the super typhoon Guchol-2012's passage and high detection without typhoon passage. () The Authors. Published by SPIE under a Creative Commons Attribution 4.0 Unported License. Distribution or reproduction of this work in whole or in part requires full attribution of the original publication, including its DOI. [DOI: 10.1117/1.JRS.13.047502]
\end{abstract}

Keywords: electro-optic identification sensor; electro-optical detection simulator; image quality; maximum detectable depth; mine countermeasure; tropical storm.

Paper 190489L received Jul. 2, 2019; accepted for publication Oct. 30, 2019; published online Nov. 18, 2019.

\section{Introduction}

For almost a century, the United States Navy has relied on acoustic sensors to map, detect threats or obstacles, and transmit information. However, with limited resources available and the desire to limit exposure to equipment and crew, alternative methods to conduct operations in mine warfare, antisubmarine warfare, and naval special warfare were developed. ${ }^{1}$ One such development is the use of electro-optical identification (EOID) sensors in conjunction with acoustic sensors to detect, classify, localize, and identify sea mines. ${ }^{2}$ EOID systems have become integral components in mine countermeasures operations and support mine identification missions by imaging objects that reside in water volume (moored and drifting mines) or on seabed (bottom and close-tethered mines). ${ }^{3}$ With the sensor development, the U.S. Navy has developed the electro-optical detection simulator (EODES) ${ }^{4}$ to identify quality of optical detection. The EODES is included in the Oceanographic and Atmospheric Master Library. It has a number of applications, such as detecting harmful objects beneath the surface or on the bottom of the ocean floor, tracking moving underwater objects, and communicating with either stationary or moving objects and vessels under the surface (Fig. 1).

Tropical storms, especially typhoons/hurricanes, generate strong surface wind stress that enhances the currents, waves, and turbulences, and in turn changes the absorption and scattering of the water and constituents within, such as particles of various origins, including algal cells, detritus, sediments, plankton, and even bubbles near the surface. This increases significantly the beam attenuation coefficient and in turn reduces the quality of EOID. ${ }^{5}$ Typhoons often hit the western North Pacific Ocean. ${ }^{6}$ However, little attention has been paid to the effects of typhoon/ hurricane's passage on optical detection, despite evidence suggesting that the strong winds significantly affect underwater IOPs such as beam attenuation coefficient and in turn the quality of EOID. ${ }^{7}$

*Address all correspondence to Peter C. Chu, E-mail: pcchu@nps.edu 


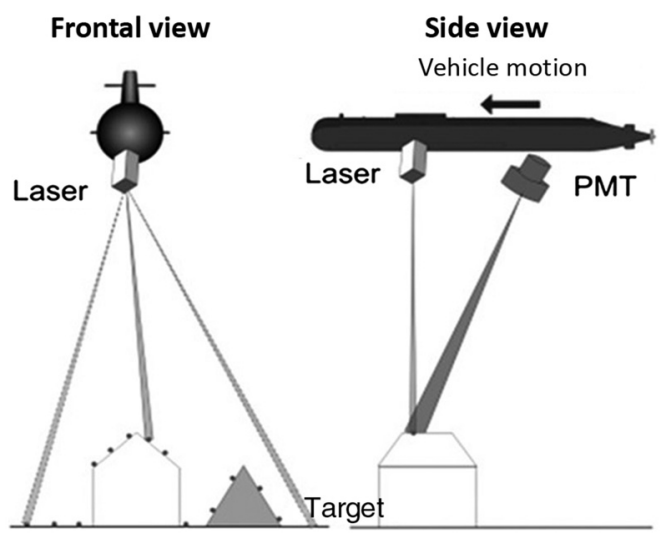

Fig. 1 Front and side views of a synchronous series EOID system (after Ref. 3).

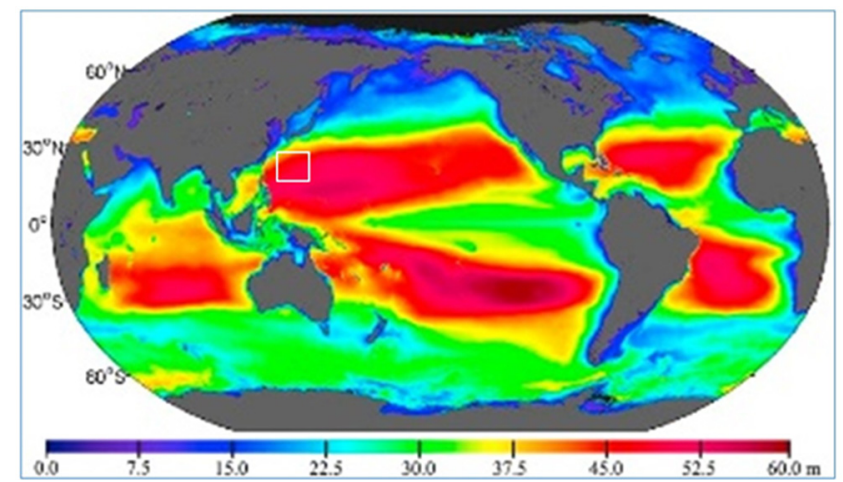

(a)

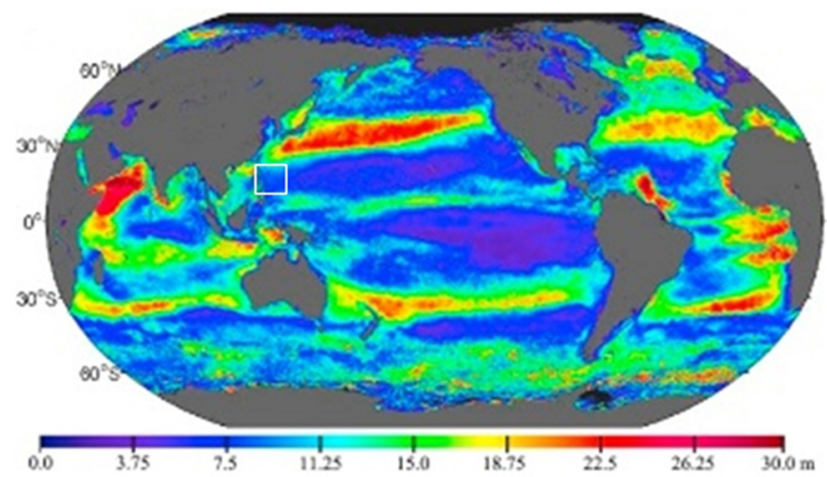

(b)

Fig. 2 Global distributions of (a) the climatological annual mean SDD (m) and (b) absolute seasonal amplitude (maximum - minimum) of the climatological monthly mean SDD $(\mathrm{m})$ derived from the SeaWiFS data over the period of September 1997 to November 2010 (from Ref. 8). Note that the area $\left(124^{\circ} \mathrm{E}-134^{\circ} \mathrm{E}\right.$ and $\left.15^{\circ} \mathrm{N}-27^{\circ} \mathrm{N}\right)$ bounded by the white lines shows high transparency with low variability.

To fill the gap, we choose a typhoon influenced area of high ocean transparency with low seasonal optical variability. The Secchi disk depth (SDD) is a key index of water transparency. Figure 2 shows the global climatological annual mean SDD and its absolute seasonal amplitude (maximum - minimum) derived from the satellite observations by the sea-viewing wide fieldof-view sensor $(\mathrm{SeaWiFS}) .^{8}$ The area $\left(124^{\circ} \mathrm{E}-134^{\circ} \mathrm{E}\right.$ and $\left.15^{\circ} \mathrm{N}-27^{\circ} \mathrm{N}\right)$, bounded by white lines in Fig. 2, is characterized as high transparency with low seasonal variability. Since seasonal and spatial differences in phytoplankton concentrations are low in this area, it is a perfect place to investigate the effect of tropical storms on the optical detection. 


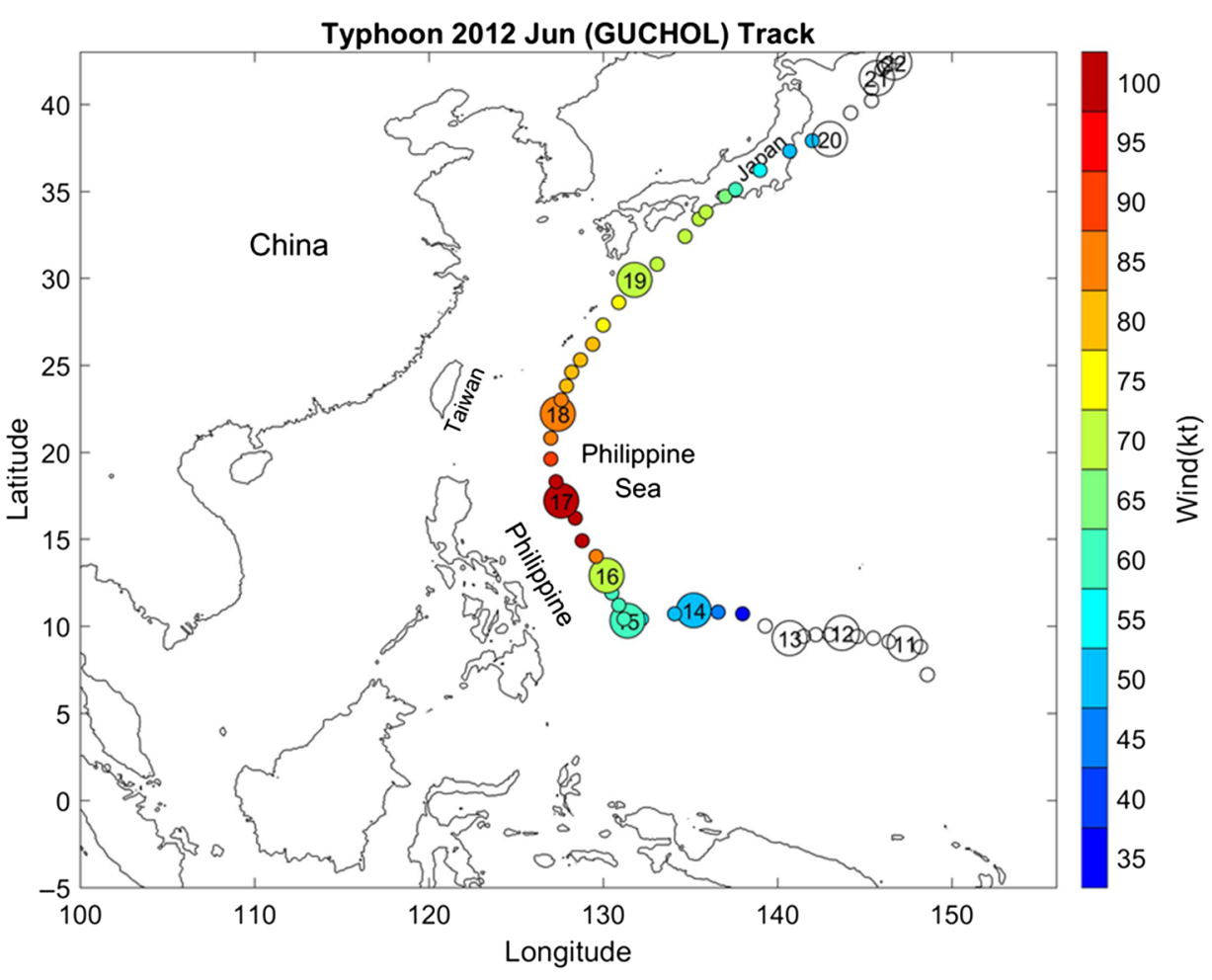

Fig. 3 Geography of the western North Pacific Ocean and track of super typhoon Guchol-2012 with strength. The integers in circles indicate the dates in June 2012. The colors in circles represent the strength of Guchol.

In 2012, a tropical disturbance formed south-southeast of Pohnpei on June 7 and was upgraded to a tropical depression on June 10. The system later intensified in favorable conditions and reached typhoon intensity (i.e., typhoon Guchol) on June 15. It reached super typhoon status on June 16 and 17, before making landfall over Japan as a typhoon on June 19 (Fig. 3). Guchol brought heavy rain and strong winds in the western Pacific Ocean near Japan on June 19 and 20. Investigation of EOID quality after typhoon passage in comparison to that without typhoon activities shows the typhoon effect. The IOPs were measured from Seagliders of the Naval Oceanographic Office (NAVOCEANO) during two different periods: (a) June 25 to 30, 2012, which is 7 days after super typhoon Guchol's passage and (b) January 9 to February 28, 2014, with no typhoon activities. The Navy's EODES is integrated with the two sets of IOPs and the quality of optical detection is identified. The reminder of this paper is outlined as follows. Section 2 describes observed IOPs with and without typhoon passage. Section 3 describes the Navy's EODES. Section 4 shows the super typhoon Guchol's effect. Section 5 presents the conclusions.

\section{IOPs with and without Typhoon Passage}

The glider is a remote operator programmed to perform a series of downward and upward tracks while collecting various oceanographic parameter data using various installed sensor packages. It can position itself at the ocean surface with a 45-deg downward angle to present the antenna array skyward to facilitate two-way satellite communications. The NAVOCEANO Seaglider has the Seabird Electronics SBE 41 CP CTD sensor (hydrographic measurement) and WET Lab's beam attenuation meter (optical measurement). ${ }^{9}$

Profile data of three Seagliders were obtained from the NAVOCEANO. Among them, two Seagliders (NG226 and NG232) were deployed from a survey ship in the area where super typhoon Guchol passing by 7 days ago. They were $15 \mathrm{~min}$ and $223 \mathrm{~m}$ apart: UTC 03:19, June 25, 2012 at $\left(25^{\circ} 30^{\prime} 20^{\prime \prime} \mathrm{N}\right.$ and $\left.131^{\circ} 59^{\prime} 51^{\prime \prime} \mathrm{E}\right)$ for NG226 [blue trajectory in Figs. 4(a) and 4(b)] 

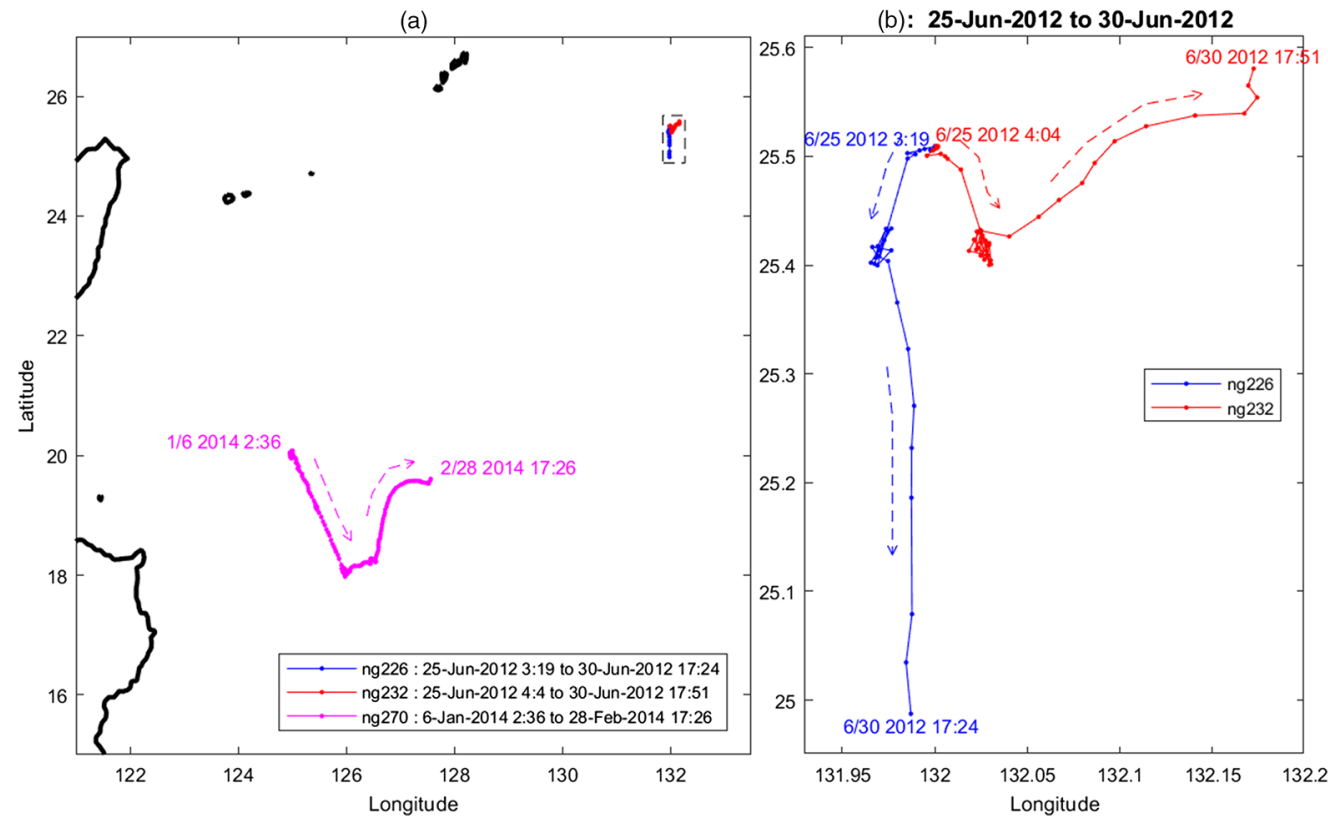

Fig. 4 Tracks of (a) NAVOCEANO Seagliders NG270 during January 9 to February 28, 2014 (red), without typhoon activity, as well as Seagliders (NG226 and NG232) during June 25 to 30, 2012 (blue), after super typhoon Guchol's passage and (b) zoomed-in view of (NG226 and NG232).

and UTC 03:34, June 25, 2012, at $\left(25^{\circ} 30^{\prime} 27^{\prime \prime} \mathrm{N}\right.$ and $\left.131^{\circ} 59^{\prime} 55^{\prime \prime} \mathrm{E}\right)$ for NG232 [red trajectory in Figs. 4(a) and 4(b)]. The two Seagliders took very different trajectories despite they were very close (only $223 \mathrm{~m}$ apart) initially with NG226 drifting southwestward and then southward and NG232 drifting southeastward and then northeastward. On June 30, 2012, NG226 was located at $\left(24^{\circ} 59^{\prime} 27^{\prime \prime} \mathrm{N}\right.$ and $\left.131^{\circ} 59^{\prime} 26^{\prime \prime} \mathrm{E}\right)$ on UTC 17:24; however, NG232 was located at $\left(25^{\circ} 34^{\prime} 50^{\prime \prime} \mathrm{N}\right.$ and $132^{\circ} 10^{\prime} 20^{\prime \prime}$ E) on UTC 17:51. Such strong bifurcation of ocean currents was generated at the wake of super typhoon Guchol. The third Seaglider (NG270) was underwater during January 6 to February 28, 2014, without any typhoon activities [magenta trajectory in Fig. 4(a)]. The beam attenuation coefficient $c(470 \mathrm{~nm})$ measured by NG 226 (59 profiles) and NG 232 (86 profiles) during June 25 to 30, 2012, after super typhoon Guchol passage [Figs. 5(a) and 5(b)] is large with horizontally averaged values (red solid profiles) generally $>0.8 \mathrm{~m}^{-1}$. The beam attenuation coefficient $c(470 \mathrm{~nm}$ ) measured by NG 270 ( 825 profiles) during January 6 to February 28, 2014, with no typhoon activity (Fig. 6) is much smaller with horizontally averaged values $<0.05 \mathrm{~m}^{-1}$.

\section{Navy's EODES}

The EODES is the Navy's standard model for identification of quality in optical detection. It simulates the propagation of a narrow, highly collimated beam of light (e.g., laser) through a scattering and absorbing seawater where the IOPs vary in the direction of the beam axis. It provides tactical performance prediction for the laser line scan (LLS) sensor of several AQS-24a systems for mine countermeasure in the fleet. ${ }^{4,10}$ The simulator consists of four modules: (a) utility, (b) radiative transfer, (c) EOID sensors and systems, and (d) environmental state.

\subsection{Utility}

The utility modules are numerical codes/functions to solve the radiative transfer equation (RTE) using the fast Fourier transform. These modules take into account the details of the system configuration and operation, the influence of optical properties of the water column, presence of ambient light, and the correlation between system resolution, optical blurring, and signal-tonoise. Inputs for this code include sensor type, laser power, vehicle towing altitude above bottom, and information on the vertical optical environment. 


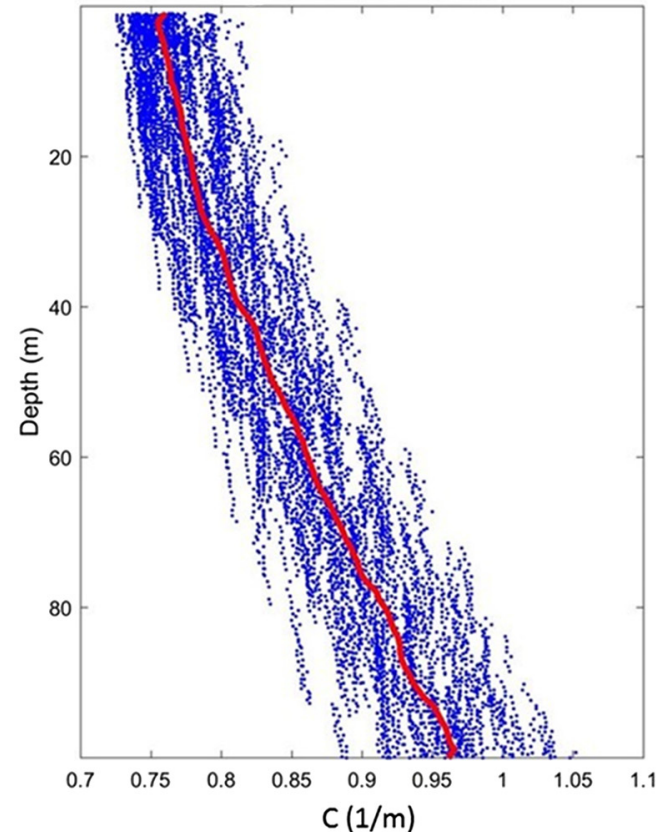

(a)

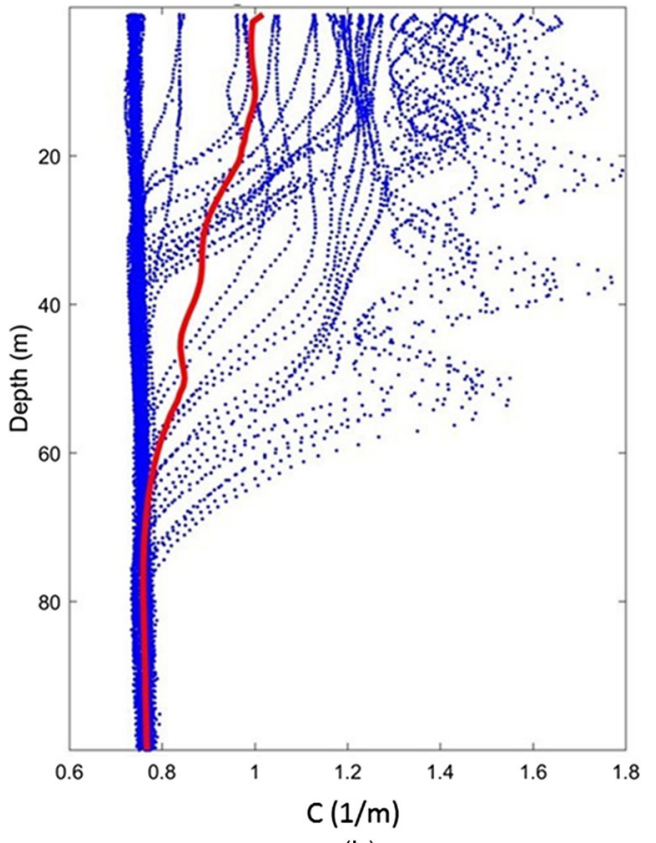

(b)

Fig. 5 Beam attenuation coefficient $c(470 \mathrm{~nm}$ ) profiles collected from (a) glider NG 226 (59 profiles) and (b) glider NG 232 (86 profiles) June 25 to 30, 2012 (after super typhoon Guchol passage). The red solid profiles are horizontally averaged values generally $>0.8 \mathrm{~m}^{-1}$.

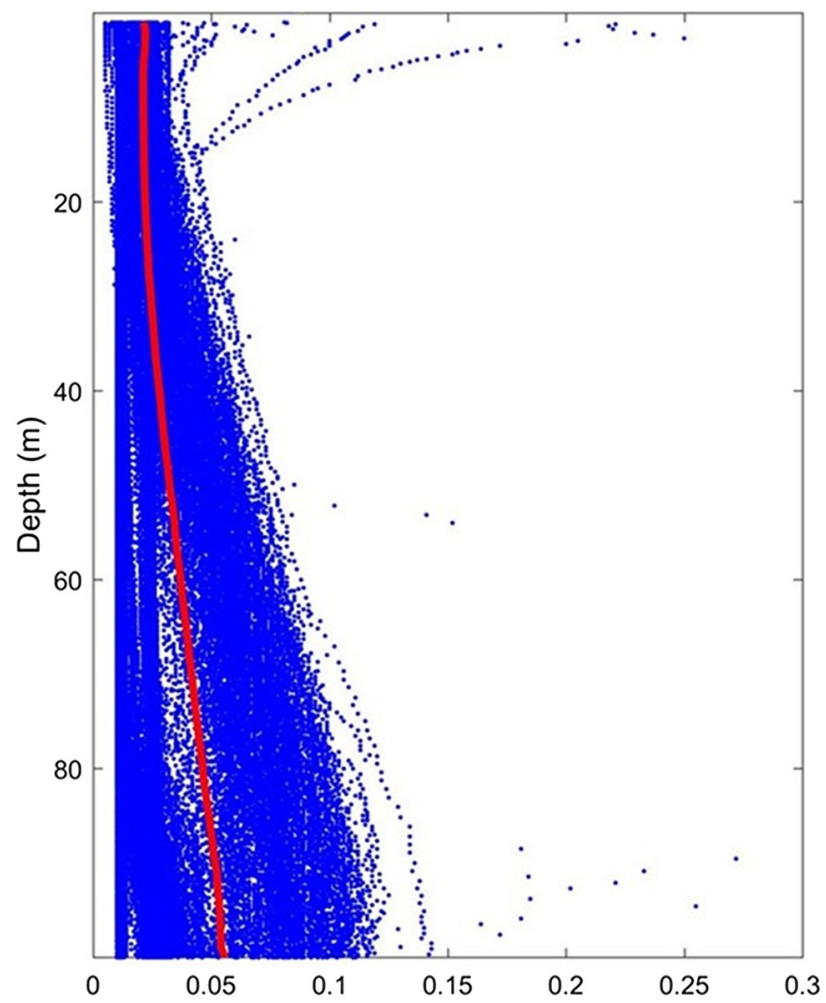

Fig. 6 Beam attenuation coefficient $c(470 \mathrm{~nm})$ profiles collected from glider NG 270 (825 profiles) January 6 to February 28, 2014, with no typhoon activity. The red solid profiles are horizontally averaged values generally $<0.05 \mathrm{~m}^{-1}$. 


\subsection{RTE}

The theoretical base is the RTE under the small-angle approximation (SAA) for scattering and that temporal dispersion is negligible. ${ }^{11}$ Let the laser beam axis pointing in the $z$ direction (i.e., nadir radiative transfer, downward positive), along track in the $x$ direction, and cross track in the $y$ direction. The RTE for a given light frequency with SAA is an integral-differential equation for the radiance $L(z, \mathbf{x}, \mathbf{n})\left[\mathrm{W} /\left(\mathrm{m}^{2} \mathrm{sr}\right)\right]$ :

$$
\left[\frac{\partial}{\partial z}+\mathbf{n} \bullet \nabla+c(z)\right] L(z, \mathbf{x}, \mathbf{n})=b(z) \int_{-\infty}^{\infty} \beta\left(\left|\mathbf{n}-\mathbf{n}^{\prime}\right|\right) L\left(z, \mathbf{x}, \mathbf{n}^{\prime}\right) \mathrm{d} \mathbf{n}^{\prime},
$$

where $\mathbf{x}=(x, y)$ is the position vector in the transverse plane; $\nabla=(\partial / \partial x, \partial / \partial y)$ is the transverse gradient; $\mathbf{n}=(\xi, \eta)$ is the projection of direction vector onto the transverse plan with $\mathrm{d} \mathbf{n}=\mathrm{d} \xi \mathrm{d} \eta$; $c(z)$ and $b(z)$ are the depth-dependent beam attenuation and volume scattering coefficients. The ratio $\omega=b / c$ is defined as the single scattering albedo. With higher albedo, collecting multiply scattered light is more because the absorption is lower. Conversely, with lower albedo (increased absorption), scattered light is less since absorption is higher. The albedo $(\omega)$ for light with wavelength of $514 \mathrm{~nm}$ is 0.247 for the clear ocean, 0.551 for the coastal ocean, and 0.833 for a turbid harbor. At $470 \mathrm{~nm}, \omega$ would be higher and less variable because lower absorption than at $514 \mathrm{~nm} .{ }^{12}$ Thus the value of $\omega$ for our study area (western North Pacific) was taken as 0.75 , the average between $0.60(>0.551)$ and $0.90(>0.833)$. The Seagliders measure the transversely averaged $c(z)$. With the single scattering albedo, the volume absorption (a) and scattering coefficients are given by

$$
a(z)=(1-\omega) c(z), \quad b(z)=\omega c(z)
$$

$\beta$ is the axisymmetric scattering phase function, which is normalized by

$$
2 \pi \int_{0}^{\pi} \beta(\alpha) \sin (\alpha) \mathrm{d} \alpha=1
$$

where $\alpha$ is the deflection angle due to a scattering event.

\subsection{EOID Sensors and Systems}

For underwater EOID applications, a highly collimated, monochromatic laser light source is typically used. Diffuse solar illumination of the optical medium and the scene also tends to be present. Loosely speaking, radiation emanating or reflecting from the scene is beneficial to the imaging process, whereas energy added to the path from any other source is detrimental. Let the target and sensor be at depths $z_{D}$ and $z_{S}$. The laser source and collector are separated by a distance $d_{S C}$. When the source and collector are separated, the collector aperture (or laser aperture) must by tilted at an angle $\theta_{C}$ so that the laser beam axis and collector line-of-sight intersect near the target scene depth. The source-collector separation $d_{S C}$ and the collector angle $\theta_{C}$ determine the relative along-track offset $\mu$ (see Fig. 7)

$$
\mu(z)=d_{S C}-\left(z-z_{S}\right) \tan \theta_{C}
$$

between the laser beam axis and collector line-of-sight at depth $z$. Ideally,

$$
\mu\left(z_{D}\right)=0
$$

such that the source and collector axes intersect at the target plane. The laser aperture half-angle $\alpha_{s}$ characterizes the axisymmetric angular variation in emitted light for the narrow, collimated laser beam, and it corresponds to the angular variation of emitted light in the case of a fan beam. Note that the fan beam illuminates the entire cross-track field of view instantaneously.

In the LLS sensor, the relative edge response (measuring the blurring and contrast loss of image) depends on the optical transfer function of the system. A simplified rating scale is used to measure relative performance, which is based on a predefined scale using a simple traffic light 


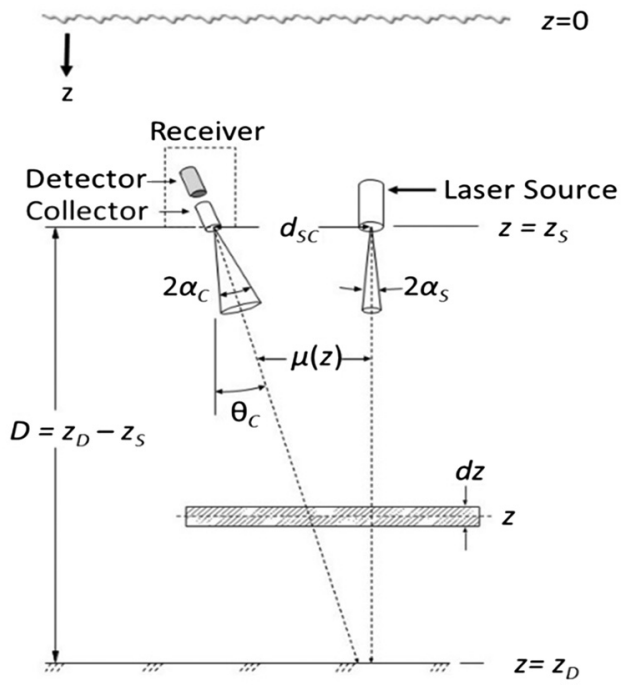

Fig. 7 Illustration of an EODES system (from Ref. 10).

decision aid, i.e., image quality (IQ) of red (no go), yellow (questionable), and green (go). Such a rating is a function of ground sampled distance (GSD) and signal-to-noise ratio (SNR). The GSD in the LLS sensor measures the image resolution. In the fan-type beam, the along-track $\left(\mathrm{GSD}_{a}\right)$ and cross-track $\left(\mathrm{GSD}_{c}\right)$ values are given by ${ }^{4}$

$$
\mathrm{GSD}_{a}=15 U / \Omega, \quad \mathrm{GSD}_{c}=2\left(z_{D}-z_{S}\right) \tan \left(\theta_{C}\right) / N,
$$

where $U$ is the platform speed $\left(\mathrm{m} \mathrm{s}^{-1}\right), \Omega$ is the spindle rotation rate (rpm), and $N$ is the number of pixels in the cross-track direction across entire swath width (Table 1).

Table 1 EOID system parameters and operational settings for the LLS system (from Ref. 4).

\begin{tabular}{lcc}
\hline \hline Parameter & Unit & Value \\
\hline Laser power $(P)$ & $\mathrm{W}$ & 0.5 \\
Laser aperture & Radian & 0.001 \\
Along-track collector aperture & Radian & 0.002 \\
Cross-track collector aperture & Radian & 0.002 \\
Cross-track angular field of view $\left(2 \theta_{C}\right)$ & Degree & 70.0 \\
Number of cross-track pixels $(N)$ & - & 1024 \\
Collector area & $\mathrm{m}{ }^{2}$ & 0.002 \\
Source-collectors separation distance & $\mathrm{M}$ & 0.4 \\
Spindle rotation rate $(\Omega)$ & $\mathrm{RPM}$ & 4000.0 \\
Photomultiplier tube efficiency & - & 0.11 \\
Source transmission coefficient & - & 0.5 \\
Collector transmission coefficient & - & 0.5 \\
Platform speed $(U)$ & $\mathrm{M}$ & 200.0 \\
Platform (sensor) depth $\left(z_{S}\right)$ & $\mathrm{m} \mathrm{s}^{-1}$ & 4.0 \\
Water or target depth $\left(z_{D}\right)$ & & 193.0 \\
\hline \hline
\end{tabular}




\subsection{Ambient (Solar) Light}

The solar altitude $\Upsilon$ is the angle the Sun's rays make with the nominally planar ocean surface. In air, the Sun's rays make an angle $\theta_{a}$ with the normal to the nominally flat ocean surface, where

$$
\theta_{a}=\pi / 2-\Upsilon
$$

The refracted angle in the water $\theta_{w}$ is related to the incident angle in the air $\theta_{a}$ by the Snell's law

$$
n_{a} \sin \theta_{a}=n_{w} \sin \theta_{w}, \quad n_{a}=1, \quad n_{w}=1.33
$$

where $n_{a}$ and $n_{w}$ are the indices of refraction in air and water, respectively. Using Eq. (8), the known solar elevation $\Upsilon$ and the downwelling solar irradiance in water column at the depth $z$ is

$$
E(z)=T_{a w} \frac{\cos \theta_{w}}{\cos \theta_{a}} E_{0} \exp \left[-\int_{z_{0}}^{z} K_{d}\left(z^{\prime}\right) \mathrm{d} z^{\prime} / \cos \theta_{w}\right],
$$

where $T_{a w}$ is the air-to-water transmission coefficient depending on $\theta_{a}$ and $\theta_{w}$ by the Fresnel formula, $E_{0}$ is the downwelling irradiance in air just above the water surface $\left(z=z_{0}\right)$, and $K_{d}(z)$ is the diffuse attenuation coefficient ${ }^{13}$

$$
K_{d}(z)=a(z)+0.0254 b(z)
$$

where $a(z)$ and $b(z)$ are the absorption and back scattering coefficients.

\subsection{Image Quality}

The IQ depends on the GSD (i.e., image resolution), the relative edge response quantifying the blurring, or loss of edge detail, and the SNR measuring the image corruption due to shot noise and including the effects of ambient light pollution and laser backscatter. ${ }^{4,14}$ In the EODES, the predicted IQ rating is measured on a scale from 0 to 10 :

$$
\mathrm{IQ}=\left\{\begin{array}{ll}
\geq 7 & \text { high confidence in identification } \\
\in[4,7) & \text { moderate level of confidence } \\
<4 & \text { low level of confidence }
\end{array} .\right.
$$

Since IQ $=7$ is the minimum value for high confidence in identification, the EODES model sets a value of IQ $=7$ as the threshold for confident identification of targets. Generally, the IQ rating will decrease with $D$. Its maximum value $D_{\max }$ (corresponding to IQ $=7$ ) represents the critical condition. Depth beyond $D_{\max }$, the system will not be able to resolve enough detail to identify the target.

\section{Effect of Super Typhoon Guchol}

Detection quality of EOID systems depends on the environment. If waters are highly turbid or have a significant amount of absorbent materials suspended in the water column, the effectiveness of these sensors is low due to the degradation of the optical signal. The EODES needs environmental input such as vertical profiles of scattering coefficient $b(z)\left(\mathrm{m}^{-1}\right)$, beam attenuation coefficient $c(z)\left(\mathrm{m}^{-1}\right)$, volume back scattering phase function $\beta_{\pi}(z)\left(\mathrm{m}^{-1} \mathrm{str}^{-1}\right)$, ambient (solar) light such as solar irradiance and altitude at the ocean surface, and the corresponding diffuse attenuation coefficient $K_{d}(z)\left(\mathrm{m}^{-1}\right)$. The beam attenuation coefficient $c(z)$ is the only IOP observed from the Seaglider. The other environmental parameters are calculated. With the albedo $\omega$, we compute the volume absorption coefficient $a(z)$ and scattering coefficient $b(z)$ using (2). With $a(z)$ and $b(z)$, we calculate the diffuse attenuation coefficient $K_{d}(z)$ using Eq. (10).

The cross sections of the beam attenuation coefficient $c(z)$ during January 6 to February 28, 2014, without typhoon activity along the track of the NAVOCEANO Seaglider NG270 [Fig. 8(a)] show small values $c<0.05 \mathrm{~m}^{-1}\left(10^{-1.3}\right.$ to 0.05 and $10^{-1.9}$ to 0.013$)$. The corresponding $D_{\max }$ 

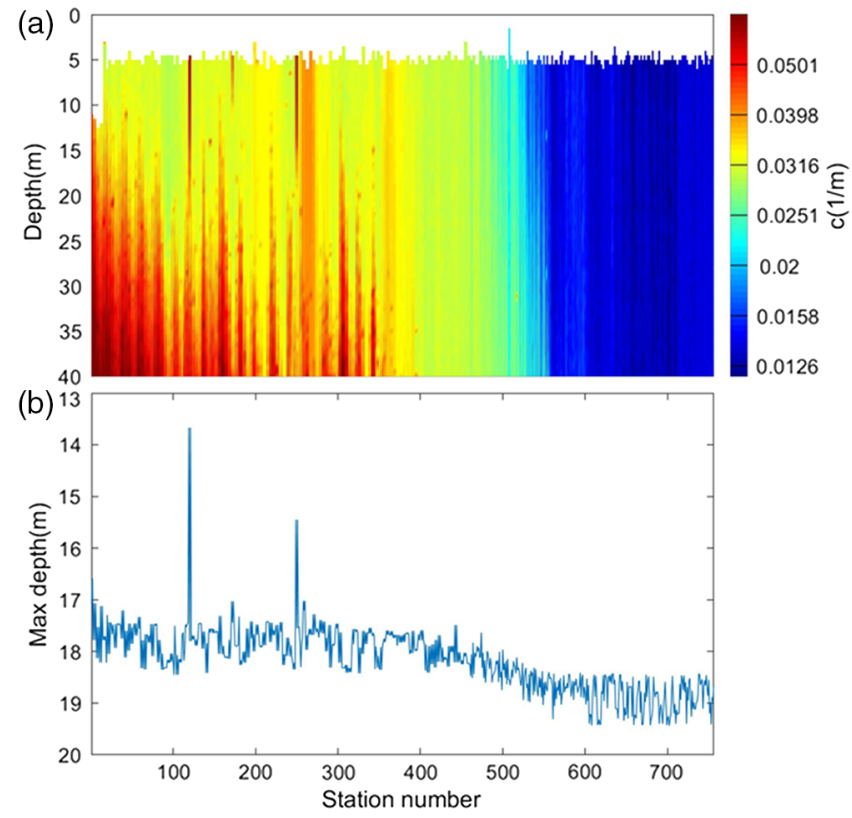

Fig. 8 Cross section of observed volume attenuation coefficient $c(z)$ along the tracks of NAVOCEANO Seaglider NG270 during January 6 to February 28, 2014, (red) (a) without typhoon activity and (b) simulated maximum detectable depth by EODES $\left(D_{\max }\right)$. The horizontal axis shows the glider's location along the magenta-colored track in Fig. 5(a) with station-1 located at $\left(19^{\circ} 36^{\prime} 32^{\prime} \mathrm{N}\right.$ and $\left.124^{\circ} 58^{\prime} 56^{\prime \prime} \mathrm{E}\right)$ on 05:01 UTC, January 09, 2014, and station-825 (19 $59^{\prime}$ $27^{\prime \prime} \mathrm{N}$ and $127^{\circ} 34^{\prime} 05^{\prime \prime} \mathrm{E}$ ) at 17:26 UTC, February 28,2014 . It is noted that there was no typhoon passing by during that period.

simulated by the EODES usually fluctuates between 17 and $19 \mathrm{~m}$ with two lower spikes of 13.7 and $15.4 \mathrm{~m}$ [Fig. 8(b)], which indicates the feasibility of using EOID for detection.

On the other hand, the cross sections of the beam attenuation coefficient $c(z)$ during January 25 to 30,2012 , after super typhoon Guchol's passage is larger than $0.74 \mathrm{~m}^{-1}\left(10^{-0.13}\right.$ to 0.74$)$ along the tracks of the NAVOCEANO Seaglider NG226 [Fig. 9(a)] and $0.79 \mathrm{~m}^{-1}\left(10^{-0.1}\right.$ to 0.79$)$ along the NAVOCEANO Seaglider NG232 [Fig. 9(b)]. The corresponding $D_{\max }$ simulated by the EODES usually fluctuates between 3.4 and $4.6 \mathrm{~m}$ along NG226 [Fig. 9(c)] and 2.3 and $4.5 \mathrm{~m}$ along NG232 [Fig. 9(d)]. This indicates that the super typhoon Guchol 1 reduced the maximum detectable depth by about $15 \mathrm{~m}$ after 7 to 13 days passage.

\section{Conclusion}

This study identifies the typhoon effects on EOID in the western North Pacific Ocean using the Navy's EODES with the data collected by three NAVOCEANO Seagliders. The beam attenuation coefficient $c(470 \mathrm{~nm})$ was measured during June 25 to 30, 2012, after super typhoon Guchol's passage and from January 6 to February 28, 2014, with no typhoon activity. Huge difference was found in the horizontally averaged $c$ with $>0.74 \mathrm{~m}^{-1}$ during typhoon Guchol's passage and with much smaller values $<0.05 \mathrm{~m}^{-1}$ without typhoon activity. The Navy's EODES is integrated using observed IOPs from the NAVOCANO Seagliders with and without the influence of typhoon. The simulated results show that the super typhoon Gochol largely reduced the maximum detectable depth of EOID by about $15 \mathrm{~m}$ in comparison to without typhoon activity. We note that the results only show the strong typhoon effect through comparison between NG226, NG232, and NG270 during the two periods: June 25 to 30, 2012, and January 6 to February 28, 2014. These two short durations are not enough to conclude and affirm the feasibility of using EOID in the western North Pacific Ocean without typhoon passage because it is well known that the IOPs of the underwater channel can be easily affected by phenomena such as wind, surface waves, optical turbulences, and water currents. It will be investigated in future studies using more complete dataset. 

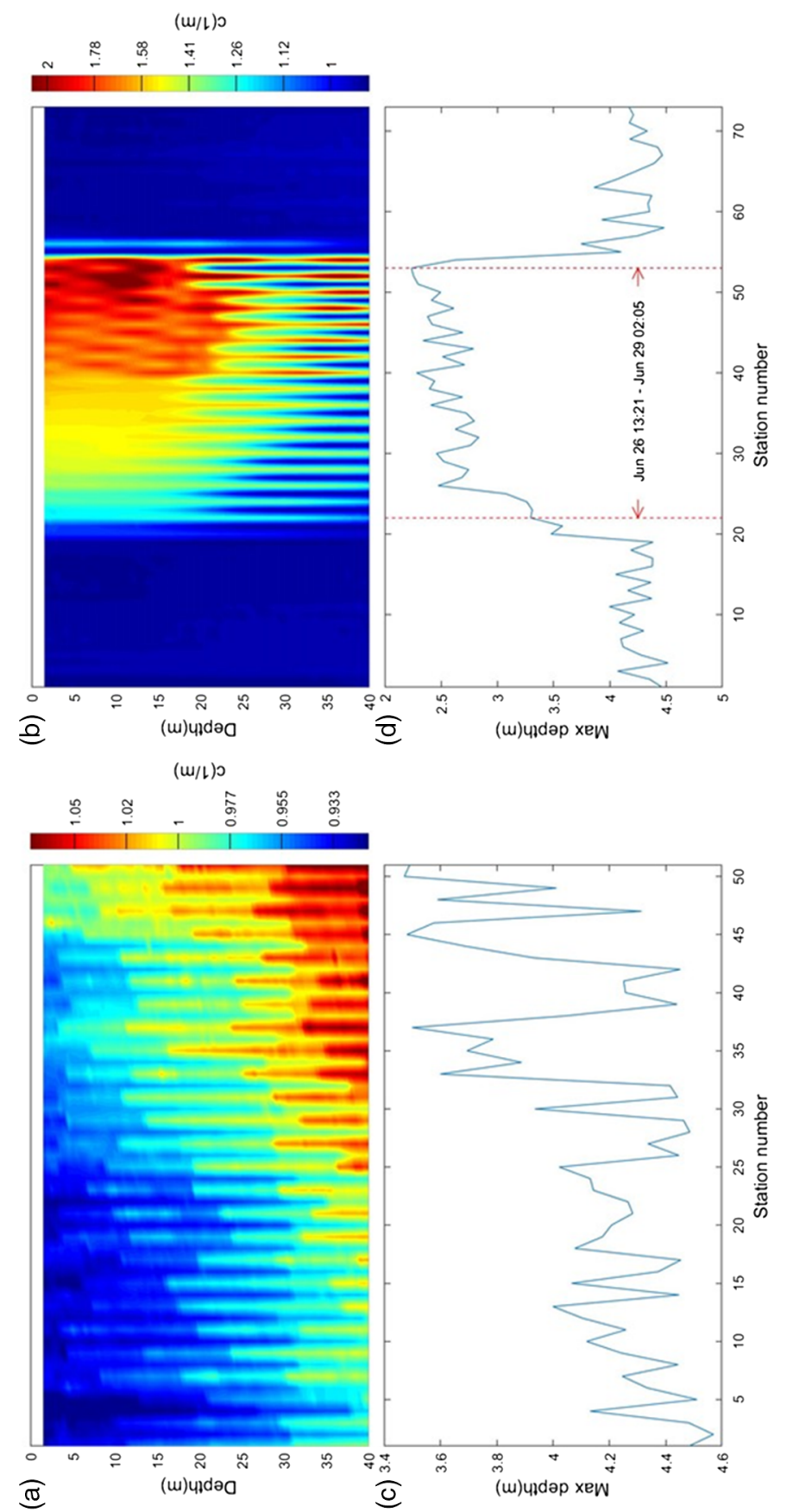

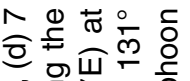

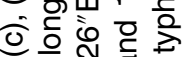
ลิ สิ สิ ฮั 등 응

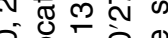
유 으 후용

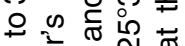

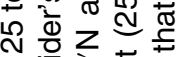

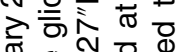

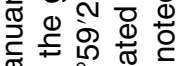

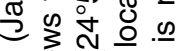
즈 음 든 Nิ क 은흐융

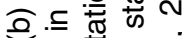

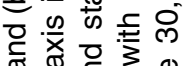

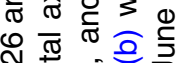

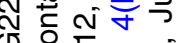
乙 Nㅡㄴ 웅 (20은 주 뉴드

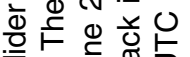
응

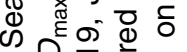

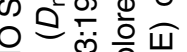
잉 응 嵌 인인은

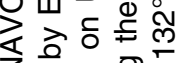

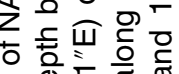

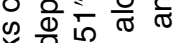
o के Z

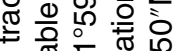
凹 웡

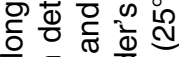
흔 는

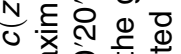
를 유 ๘ 응 누응 원 원은

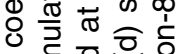
등ㅎㅇ 흐흘

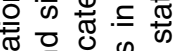

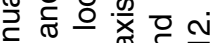
ข్ స ర్ర () 业 Nㅜㄴ 응 으

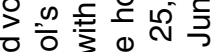

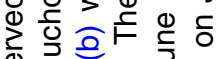
థึ寸 응 등ㅎํ유 to 등. 잉

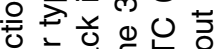

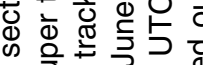
की के ठ্

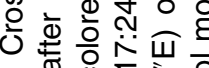
$a$ o 0 - i

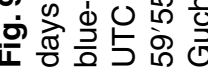




\section{Acknowledgments}

We thank the Naval Oceanographic Office for the use of optical data from three Seagliders and Dr. Thomas Giddings and Dr. Joseph Shirron at the Metron Inc. for producing the EODES model. The Office of Naval Research sponsored this research.

\section{References}

1. National Research Council, "Oceanography and mine warfare," National Academy Press, pp. 39-56 (1999).

2. J. S. Taylor and M. C. Hulgan, "Electro-optic identification research program," in OCEANS MTS/IEEE (2002).

3. Q. Y. Bing et al., "Compressive sensing underwater laser serial imaging system," J. Electron. Imaging 22(2), 021010 (2013).

4. T. E. Giddings and J. J. Shirron, "Software design document for the EODES electro-optical identification performance prediction model," CDRL Sequence No. 1, Prepared for Naval Oceanographic Office, pp. 1-113 (2011).

5. W. Hou et al., "Impacts of underwater turbulence on acoustical and optical signals and their linkage," Opt. Express 21(4), 4367-4375 (2013).

6. X. D. Wang, X. Wang, and P. C. Chu, "Air-sea interaction during rapid intensification of typhoon Fengshen (2008)," Deep Sea Res. Part-1 140, 63-77 (2018).

7. P. C. Chu et al., "Environmental effects on underwater optical transmission," Proc. SPIE 10186, 1018609 (2017).

8. X. He et al., "Recent changes of global ocean transparency observed by SeaWiFS," Cont. Shelf Res. 143, 159-166 (2017).

9. K. L. Mahoney et al., "RIMPAC 08: Naval Oceanographic Office glider operations," Proc. SPIE 7317, 731706 (2009).

10. T. E. Giddings and J. J. Shirron, "Numerical simulation of the incoherent electro-optical imaging process in plane-stratified media," Opt. Eng. 48(12), 126001 (2009).

11. L. S. Dolin, "Propagation of a narrow light beam in a random medium," Izv. Vyssh. Uchebn. Zaved. Radiofiz. 7(2), 380-382 (in Russian) (1964).

12. C. Mobley, "Ocean optics web book," 2016, http://www.oceanopticsbook.info/.

13. E. Aas, "Two-stream irradiance model for deep waters," Appl. Opt. 26(11), 2095-2101 (1987).

14. J. C. Leachtenauer et al., "General image-quality equation: GIQE," Appl. Opt. 36(32), 8322-8328 (1997).

Peter C. Chu received his PhD in geophysical sciences from the University of Chicago in 1985. $\mathrm{He}$ is a distinguished professor and chair of the Oceanography Department at the U.S. Naval Postgraduate School. He is the author of more than 190 journal papers and has written 3 books. His current research interests include environmental effects on underwater optical detection and communication. He is a fellow of the American Meteorological Society, a founding member of the Oceanography Society, a founding member of the Asia Oceania Geosciences Society, and a member of the American Geophysical Union.

Chenwu Fan received his master's degree in mechanical engineering from Donghua University, Shanghai, China, in 1982. He is an oceanographer at the Naval Ocean Analysis and Prediction Laboratory of the U.S. Naval Postgraduate School. He co-authored more than 60 journal papers. 